\title{
A General Approach TO THE StOCHASTIC ROTATION PROBLEM WITH AMENITY VALUATION
}

\author{
LUIS H. R. ALVAREZ \\ ERKKI KOSKELA
}

\author{
CESIFO WORKING PAPER NO. 857 \\ CATEGORY 8: RESOURCES AND ENVIRONMENT
}

FEBRUARY 2003
An electronic version of the paper may be downloaded
- from the SSRN website: www.SSRN.com
- from the CESifo website: www.CESifo.de




\title{
A General Approach to THE StOCHAStiC RoTATION PROBLEM WITH AMENITY VALUATION
}

\begin{abstract}
This paper presents a new approach to study the optimal rotation policy with amenity valuation under uncertainty. We first postulate the stochastic forest value and assume plausibly that monetary value of amenities is a continuous and non-negative function of forest value thus presenting the trade-off between timber revenues and amenity values. Second, instead of using a dynamic programming approach, we derive a recursive representation of the total forest value and solve the optimal rotation threshold by applying ordinary non-linear programming techniques. Third, we characterize under certain set of conditions how the properties of both the expected cumulative value and the expected marginal cumulative value, accrued from amenity services, depend on the precise nature of the monetary valuation of amenities and what is the impact of volatility on these concepts. Finally, we illustrate our results explicitly in models based on logistic growth by focusing on the role of amenity valuation and volatility of forest value in the determination of Wicksellian and Faustmannian thresholds. Our theoretical and numerical findings emphasize the crucial importance of the nature of amenity valuation for the impact of higher volatility of forest value on the rotation thresholds.
\end{abstract}

Keywords: amenity valuation, optimal Faustmannian and Wicksellian rotation policy, stochatic impulse control.

JEL Code: Q23, G26, C61.

Luis H. R. Alvarez

Department of Economics

Quantitative Methods in Management

Turku School of Economics and Business

Administration

FIN-20500 Turku

Finland

luis.alvarez@tukkk.fi
Erkki Koskela

Department of Economics

University of Helsinki

FIN-00014 University of Helsinki

Finland

Erkki.koskela@helsinki.fi 


\section{Introduction}

In the usual Faustmann approach to the optimal forest rotation forest owners are assumed to maximize the present value of net harvesting revenue. See e.g. Reed 1986 for a survey. It may be the case, however, that forest owners are interested not only in the present value of net harvesting revenue, but also in the amenity services provided by forest stands. Binkley 1981 as well as Kuuluvainen and Tahvonen 1999 among others provide in various ways some indirect empirical evidence in favor of this hypothesis (see also a survey of theoretical and empirical research about timber supply by Wear and Parks 1994). This raises the following question: How does the amenity valuation affect the privately optimal rotation in the ongoing rotations framework? The first analytical treatment to include amenity service values is the stand-level model by Hartman 1976, who shows that if amenity services are increasing with the age, then the optimal rotation age for the stand will exceed the Faustmann rotation age thereby delaying the harvest (see also Strang 1983, Bowes and Krutilla 1985 and Snyder and Bhattacharyya 1990, where the maintenance of provision costs necessary to realize a quality flow of recreational services is explicitly included). Koskela and Ollikainen 2001, 2002, have studied in the Hartman framework the impact of various types of forest taxes on the rotation age and the optimal design of forest taxes, respectively. The original Hartman model and most of its extensions, however, are deterministic so that future timber revenue and amenity values are known, which is of course a heroic assumption to be relaxed.

To our knowledge allowing for uncertainty in the framework of the Hartman model has been theoretically analyzed only in Reed 1993 and in Reed and Ye 1994, respectively. Reed 1993 assumes that both future amenity values and future timber values are uncertain and that there is a possibility of catastrophic risk e.g. via forest fire, which is modelled as a Poisson process. When both future amenity values and timber revenue are assumed to follow geometric, possibly correlated, Brownian motion processes, Reed 1993 shows that in the case of risk-neutral forest owners the forest stand is harvested if the ratio of current timber value to current amenity services exceeds a certain threshold level, which reflects the option value associated with uncertainties, i.e. the certaintyequivalence theorem does not hold. In terms of comparative statics, the rotation age is shown to become longer as the expected growth rate of timber revenue and the uncertainty of both timber value and amenity services will increase, while the rotation age becomes shorter as the expected growth rate of amenity services, the interest rate, the covariance between timber and amenity value uncertainties as well as the probability of forest fire will increase. The model assumptions in Reed and Ye 1994 are identical to those in Reed 1993 with one exception. Instead of postulating geometric Brownian motion processes for timber revenue and amenity value, Reed and Ye 1994 assume that changes in valuations of amenity services and in timber prices occur in discrete jumps at random times as geometric jump processes. Under this specification the ratio of the value of amenity services relative to timber values can be monotone (nondecreasing or non-increasing), while still stochastic implying that there is no option value associated with the decision to harvest, even though there is uncertainty in future timber and amenity values. Hence according to their findings the cause of option values seems to be not so much uncertainty per se, but rather the possibility of reversals in the direc- 
tion of the ratio between the value of amenity services and timber revenues. Conrad (2000) has applied option theory to the decision to extract resources and/or develop a wilderness area and thereby amenity dividend. He also assume both amenity values and value of resources to follow different geometric Brownian motion processes.

As for empirical applications, Conrad 1997 has presented a model where a stand of old-growth forest has a known stumpage value, and where future amenity value is uncertain and follows geometric Brownian motion. He has applied it to the Headwaters Forest, a stand of old-growth coast redwood in Northern California. Bulte et al 2002 have applied the same model to the humid Atlantic zone of Costa Rica. The main idea of these papers is to try empirically outline the impact of uncertainty about forest conservation benefits on the incentive to harvest or conserve old-growth forests.

In the papers mentioned above the authors have assumed different stochastic formulations for timber revenues and amenity values in terms of the mean growth rate (drift) and uncertainty (variance) parameters. What we do in this paper is first to postulate stochastic forest stand value and assume that monetary value of amenities is a continuous and non-negative function of the forest value thus emphasizing the trade-off between timber revenues and amenity values. Second and importantly, instead of relying on the standard dynamic programming approach, this paper follows the approach introduced in Alvarez 2001b, 2001c. The key idea is to derive an associated functional from which the optimal rotation threshold and its value can be explicitly solved in terms of exogenous quantities by solely relying on standard non-linear programming techniques. Third, we characterize under certain set of conditions how the properties of both the expected cumulative value and the expected marginal cumulative value, accrued from amenity services, depend on the precise nature of the monetary valuation of amenities and how increased volatility will affect these concepts. Finally, we illustrate our results explicitly in deterministic and stochastic models based on logistic growth. Our theoretical and numerical findings emphasize the crucial importance of the nature of amenity valuation for the impact of higher volatility of forest value on the optimal rotation thresholds.

We proceed as follows. In section 2 a general characterization of the optimal rotation problem with amenity valuation under uncertainty is done. Section 3 provides the solution to the optimal ongoing rotation problem and characterizes its various properties. The Wicksellian single rotation problem and its relationship with the Faustmannian ongoing rotation problem is presented in section 4. Our results are explicitly illustrated in section 5 in a model based on logistic growth both in the deterministic and stochastic case. Finally, there is a brief concluding section.

\section{A New Characterization of the Faustmannian Optimal Rotation Problem with Amenity Valua- tion}

In this section we characterize the optimal rotation problem when forest owners are interested both in the expected cumulative harvest revenue and in the amenity services of forest stand under the circumstances when the forest stand value and thereby the 
amenity services as a non-negative function of forest value are stochastic processes. More precisely we proceed as follows: First, we specify the dynamics of the system and define the optimal ongoing rotations problem (i.e. a stochastic impulse control problem). Second, under certain natural assumptions we end up with two linearly independent fundamental solutions and in terms of these solutions we can express the Green function of the diffusion of the forest stand value in terms of these solutions. This, interestingly, makes it possible to study the optimal rotation problem by relying on standard non-linear programming techniques.

Let $\left(\Omega, \mathcal{F},\left\{\mathcal{F}_{t}\right\}_{t \geq 0}, \mathbb{P}\right)$ be a filtered probability space, and assume that the dynamics of the stochastic forest stand value growth are described up to extinction by the generalized Itô-equation

$$
X_{t}^{\nu}=x+\int_{0}^{t} \mu\left(X_{s}^{\nu}\right) d s+\int_{0}^{t} \sigma\left(X_{s}^{\nu}\right) d s-\sum_{\tau_{k} \leq t} \zeta_{k}, \quad t \geq 0,
$$

where $\mu: \mathbb{R}_{+} \mapsto \mathbb{R}$ and $\sigma: \mathbb{R}_{+} \mapsto \mathbb{R}$ are known to be sufficiently smooth (at least continuous) mappings guaranteeing the existence of a solution for the stochastic differential equation (2.1) (cf. Borodin and Salminen 1996, pp. 46-47). In line with most studies considering population growth, we assume that the upper boundary $\infty$ of the state space is natural for the controlled diffusion in the absence of interventions (cf. Borodin and Salminen 1996, pp. 14-15), that $\lim _{x \downarrow 0} \mu(x)=0$ (i.e. that 0 is a steady-state of the controlled system in the absence of stochastic fluctuations), that the percentage growth rate $\mu(x) / x$ is non-increasing, and that $\mu(x)>0$ on $(0, \bar{x})$, where $\bar{x}>0$ is known (may be infinite). For simplicity, we will also assume that the lower boundary 0 is unattainable for the controlled diffusion in the absence of harvesting. We would like to emphasize that although this assumption rules out the cases subject to potentially finite expiration, it is satisfied by most models applied in the literature on optimal forest rotation (logistic dynamics subject to environmental stochasticity, geometric Brownian motion, etc.).

An irreversible rotation policy - an impulse control - for the system (2.1) is a possibly finite sequence

$$
\nu=\left(\tau_{1}, \tau_{2}, \ldots, \tau_{k}, \ldots ; \zeta_{1}, \zeta_{2}, \ldots, \zeta_{k}, \ldots\right)_{k \leq N} \quad(N \leq \infty),
$$

where $\left\{\tau_{k}\right\}_{k \leq N}$ is an increasing sequence of $\mathcal{F}_{t}$-stopping times (known as the rotation dates) for which $\tau_{1} \geq 0$, and $\left\{\zeta_{k}\right\}_{k \leq N}$ denote a sequence of non-negative impulses (i.e. $\zeta_{k} \geq 0$ for all $\left.k \leq N\right)$ exerted at the corresponding rotation dates $\left\{\tau_{k}\right\}_{k \leq N}$, respectively. In line with standard models considering optimal rotation policies, we assume that the process is always instantaneously driven to the exogenously given state $x_{0}$ whenever the irreversible harvesting policy is exerted. That is, we assume that if the boundary at which the harvesting opportunity is exercised is given, then the size of the subsequent rotation policy is always a known constant. We denote as $\mathcal{V}$ the class of admissible rotation policies $\nu=\left(\tau_{1}, \tau_{2}, \ldots, \ldots ; \zeta_{1}, \zeta_{2}, \ldots\right)_{k \leq N}$ and assume that $\tau_{k} \rightarrow \infty$ almost surely for all $\nu \in \mathcal{V}$ and $x \in \mathbb{R}_{+}$. As usually, we denote as

$$
\mathcal{A}=\frac{1}{2} \sigma^{2}(x) \frac{d^{2}}{d x^{2}}+\mu(x) \frac{d}{d x}
$$

the differential operator associated with the controlled process $X_{t}^{\nu}$. 
Given the stochastic dynamics of forest stand value growth described in (2.1) and our technical assumptions, we now define the the expected cumulative present value of the net revenues (including harvesting and monetary value of amenity services) from the present up to a potentially infinite future as

$$
J^{\nu}(x)=\mathbf{E}_{x}\left[\sum_{k=1}^{N} e^{-r \tau_{k}}\left(X_{\tau_{k}}^{\nu}-c\right)+\int_{0}^{\infty} e^{-r s} \pi\left(X_{s}^{\nu}\right) d s\right],
$$

where $c>0$ is the regeneration cost associated with harvesting and replanting and $\pi: \mathbb{R}_{+} \mapsto \mathbb{R}_{+}$is a given continuous and non-negative mapping measuring the revenues accrued from amenity services. In line with the literature on optimal rotation, we will assume that $x_{0}<c$. Given the definition of the expected cumulative present value of the net revenues $J^{\nu}(x)$ we consider the optimal rotation problem which is a stochastic impulse control problem

$$
V(x)=\sup _{\nu \in \mathcal{V}} J^{\nu}(x), \quad x \in \mathbb{R}_{+}
$$

and explore an admissible rotation policy $\nu^{*} \in \mathcal{V}$ for which

$$
J^{\nu^{*}}(x)=V(x), \quad x \in \mathbb{R}_{+} .
$$

Denote now as $X_{t}$ the considered diffusion describing the value of the forest stand in the absence of harvesting. As usually, we denote as $\mathcal{L}^{1}\left(\mathbb{R}_{+}\right)$the class of cash flows $f(x)$ with finite expected cumulative present values and denote this present value as

$$
\left(R_{r} f\right)(x)=\mathbf{E}_{x} \int_{0}^{\infty} e^{-r s} f\left(X_{s}\right) d s .
$$

In order to guarantee the finiteness of the objective functional (2.2), we shall assume throughout this study that the mapping $\theta(x)=\pi(x)+\mu(x)-r(x-c)$ measuring the expected growth rate of the total value of a forest stand has a finite expected cumulative present value, that is, that $\theta \in \mathcal{L}^{1}\left(\mathbb{R}_{+}\right)$. Of course, in line with this assumption, we shall also assume that the expected cumulative present value of the returns accrued from amenity services is finite as well meaning that $\pi \in \mathcal{L}^{1}\left(\mathbb{R}_{+}\right)$.

As it is known from the literature on linear diffusions, there are two linearly independent fundamental solutions, denoted as $\psi(x)$ and $\varphi(x)$, with $\psi(x)$ monotonically increasing and $\varphi(x)$ monotonically decreasing which span the set of solutions of the ordinary differential equation $((\mathcal{A}-r) u)(x)=0$ (for a complete characterization of the fundamental solutions and their boundary conditions see Borodin and Salminen 1996, pp. 18 - 19). More specifically, the Green function $G_{r}(x, y)$ of the diffusion $X_{t}$, describing the value of the forest stand, can be expressed in terms of these solutions as (cf. Borodin and Salminen 1996, p. 19)

$$
G_{r}(x, y)= \begin{cases}B^{-1} \psi(x) \varphi(y), & x<y \\ B^{-1} \psi(y) \varphi(x), & x \geq y\end{cases}
$$

where

$$
B=\frac{\psi^{\prime}(x)}{S^{\prime}(x)} \varphi(x)-\frac{\varphi^{\prime}(x)}{S^{\prime}(x)} \psi(x)>0
$$


denotes the constant Wronskian determinant of the fundamental solutions and

$$
S^{\prime}(x)=\exp \left(-\int \frac{2 \mu(x)}{\sigma^{2}(x)} d x\right)
$$

denotes the density of the scale function of $X$. The functions $\psi(x)$ and $\varphi(x)$ are also minimal in the sense that any non-trivial $r$-excessive mapping for $X$ can be expressed in terms of these mappings (more precisely, there exists an integral representation of such mappings in terms of these solutions; cf. Borodin and Salminen 1996, p. 32). Consequently, we find that if $f \in \mathcal{L}^{1}\left(\mathbb{R}_{+}\right)$, then

$$
\left(R_{r} f\right)(x)=\int_{(0, \infty)} G_{r}(x, y) f(y) m^{\prime}(y) d y,
$$

where $m^{\prime}(x)=2 /\left(\sigma^{2}(x) S^{\prime}(x)\right)$ denotes the density of the speed measure $m$ of the diffusion $X$. After having ended up technically with two linearly independent fundamental solutions and expressed the Green function of the diffusion in terms of these solutions we now move on to study the optimal ongoing rotation problem.

\section{Solution of the Stochastic Optimal Rotation Problem with Amenity Valuation}

In this section we solve the optimal ongoing rotations problem with amenity valuation with our general framework and characterize its properties. To do that we follow the approach introduced in Alvarez 2001b, 2001c. The key idea is to derive an associated functional from which the optimal rotation threshold and its value can be explicitly solved in term of exogenous variables by relying solely on standard non-linear programming techniques. More precisely, we proceed as follows: First we define the auxiliary Markovian functional, i.e. the value accrued from exercising the irreversible rotation policy at a given predetermined threshold, and show how it can be expressed in terms of the fundamental solutions $\psi(x)$ and $\varphi(x)$ presented in Section 2. Using this auxiliary Markovian functional, we show how the optimal rotation problem can be expressed as an ordinary non-linear programming problem. Second, we present a set of sufficient conditions under which a unique optimal threshold exists and under which the associated Markovian functional constitutes the value of optimal rotation problem. Third, we present a set of plausible sufficient conditions under which the cumulative present value from amenity services is concave in terms of current state and negatively related to increasing volatility of the system. We also state sufficient conditions for the negative relationship between volatility and the value of the optimal rotation policy. Finally, we characterize under certain set of conditions how the properties of both the expected cumulative present value of the revenues accrued form amenity services and its marginal value depend on the nature of the amenity valuation function and what is the impact of volatility on these concepts.

In order to accomplish these tasks, we define for $y \in\left(x_{0}, \infty\right)$ the Markovian functional $F: \mathbb{R}_{+} \mapsto \mathbb{R}$ recursively as

$$
F(x)=\mathbf{E}_{x}\left[e^{-r \tau_{y}}\left(F\left(x_{0}\right)+X_{\tau_{y}}-c\right)+\int_{0}^{\tau_{y}} e^{-r s} \pi\left(X_{s}\right) d s\right],
$$


where $\tau_{y}=\inf \left\{t \geq 0: X_{t} \geq y\right\}$. Thus, $F(x)$ can be interpreted as the value accrued from exercising the irreversible rotation policy at a given potentially suboptimal threshold $y$. After the rotation opportunity has been exercised, the diffusion $X_{t}$ is instantaneously driven to the state $x_{0}$ at which it is restarted through replantation. It is clear, and important to point out, that although the controlled process is not a diffusion because of the jumps created by the lump-sum harvesting strategy, the process $X_{t}$ behaves like a diffusion between consecutive harvesting dates and, therefore, the standard techniques apply within a rotation cycle.

Since the expected present value of the timber revenues satisfies the equation

$$
\mathbf{E}_{x}\left[e^{-r \tau_{y}}\left(X_{\tau_{y}}-c\right)\right]=x-c+\mathbf{E}_{x} \int_{0}^{\tau_{y}} e^{-r s}\left[\mu\left(X_{s}\right)-r\left(X_{s}-c\right)\right] d s,
$$

we find that $F(x)$ can be rewritten as

$$
F(x)= \begin{cases}F\left(x_{0}\right)+x-c & x \geq y \\ (x-c)+\left(R_{r} \theta\right)(x)+\left(F\left(x_{0}\right)-\left(R_{r} \theta\right)(y)\right) \frac{\psi(x)}{\psi(y)} & x<y\end{cases}
$$

where $\psi(x)$ denotes the increasing fundamental solution defined in the previous section 2. Noticing that $F(x)$ is continuous for any possible choice of $y \in\left(x_{0}, \infty\right)$ means that the auxiliary Markovian functional $F(x)$ satisfies the value-matching condition for any admissible harvesting threshold. It is now clear from (3.2) that letting $x$ tend to $x_{0}$ yields after a simple algebraic manipulation

$$
F\left(x_{0}\right)=\frac{\psi(y)\left(x_{0}-c+\left(R_{r} \theta\right)\left(x_{0}\right)\right)-\psi\left(x_{0}\right)\left(R_{r} \theta\right)(y)}{\psi(y)-\psi\left(x_{0}\right)} .
$$

This can be rewritten as

$$
F\left(x_{0}\right)=\frac{\mathbf{E}_{x_{0}}\left[e^{-r \tau_{y}}\left(X_{\tau_{y}}-c\right)+\int_{0}^{\tau_{y}} e^{-r s} \pi\left(X_{s}\right) d s\right]}{1-\mathbf{E}_{x_{0}}\left[e^{-r \tau_{y}}\right]},
$$

which describes the expected cumulative present value of future harvests and amenity services accrued over a rotation cycle terminated whenever $X_{t}$ becomes greater than $y$. Inserting (3.3) into (3.2) then finally yields

$$
F(x)= \begin{cases}\left(x_{0}-c\right)+\left(R_{r} \theta\right)\left(x_{0}\right)+u(y) \psi\left(x_{0}\right)+x-c & x \geq y \\ (x-c)+\left(R_{r} \theta\right)(x)+u(y) \psi(x) & x<y\end{cases}
$$

where

$$
u(y)=\frac{x_{0}-c+\left(R_{r} \theta\right)\left(x_{0}\right)-\left(R_{r} \theta\right)(y)}{\psi(y)-\psi\left(x_{0}\right)} .
$$

It is worth observing that the continuity of the functional $\left(R_{r} \theta\right)(x)$, the monotonicity of the increasing fundamental solution $\psi(x)$, and our assumption $x_{0}<c$ imply that

$$
\lim _{x \downarrow x_{0}} u(x)=-\infty \quad \text { and } \quad \lim _{x \uparrow x_{0}} u(x)=\infty
$$


which demonstrates that $u(x)$ is discontinuous at the restarting state $x_{0}$. Given the auxiliary mapping $u(y)$, consider now the following ordinary non-linear programming problem

$$
u\left(x^{*}\right)=\sup _{y \in\left[x_{0}, \infty\right)} u(y)
$$

where $x^{*}=\operatorname{argmax}_{y \in\left[x_{0}, \infty\right)}\{u(y)\}$, and define the functional $F^{*}(x)$ as

$$
F^{*}(x)= \begin{cases}\left(x_{0}-c\right)+\left(R_{r} \theta\right)\left(x_{0}\right)+u\left(x^{*}\right) \psi\left(x_{0}\right)+x-c & x \geq x^{*} \\ (x-c)+\left(R_{r} \theta\right)(x)+u\left(x^{*}\right) \psi(x) & x<x^{*}\end{cases}
$$

It is now clear that $F^{*}(x)$ represents the value of the stationary Faustmannian rotation policy with amenity valuation which can be described as follows: there is a state $x^{*} \in$ $\left(x_{0}, \infty\right)$ at which the controlled diffusion modelling the value of the forest stand is instantaneously driven to the state $x_{0} \in \mathbb{R}_{+}$where it is immediately restarted. Hence, given the definition of the functional $F^{*}(x)$ and the admissibility but the (potential) sub-optimality of the implemented policy, we find that $V(x) \geq F^{*}(x)$ for all $x \in \mathbb{R}_{+}$. Therefore, for the verification of the optimality of the proposed policy and its value it is sufficient to establish conditions under which $V(x) \leq F^{*}(x)$.

Given the continuous differentiability of $u(y)$ on $\mathbb{R}_{+} \backslash\left\{x_{0}\right\}$, it is now clear that if an interior optimal threshold $x^{*} \in\left(x_{0}, \infty\right)$ locally maximizing $u(y)$ exists, then we necessarily have $u^{\prime}\left(x^{*}\right)=0$ implying that

$$
u\left(x^{*}\right)=-\frac{\left(R_{r} \theta\right)^{\prime}\left(x^{*}\right)}{\psi^{\prime}\left(x^{*}\right)}
$$

Now we can show the following

Lemma 3.1. Assume that an optimal threshold $x^{*}$ maximizing $u(y)$ on the set $\left(x_{0}, \infty\right)$ exists. Then, $F^{*}(x)$ is continuously differentiable on $\mathbb{R}_{+}$and twice continuously differentiable on $\mathbb{R}_{+} \backslash\left\{x^{*}\right\}$. Moreover, $F^{*}(x)$ satisfies the boundary value problem

$$
\begin{aligned}
& \frac{1}{2} \sigma^{2}(x) F^{* \prime \prime}(x)+\mu(x) F^{* \prime}(x)-r F^{*}(x)+\pi(x)=0 \quad x \in\left(0, x^{*}\right) \\
& F^{*}\left(x^{*}\right)=x^{*}-c+F^{*}\left(x_{0}\right), \quad F^{* \prime}\left(x^{*}\right)=1 .
\end{aligned}
$$

Proof. See Appendix A.

Lemma 3.1 establishes that whenever the mapping $u(x)$ attains a unique maximum on $\left(x_{0}, \infty\right)$, the (potentially suboptimal) value $F^{*}(x)$ is stochastically of class $C^{2}\left(\mathbb{R}_{+}\right)$ (see Brekke and Øksendal 1994, 1996 for a precise definition) and satisfies on $\left(0, x^{*}\right)$ the ordinary second order differential equation $\left((\mathcal{A}-r) F^{*}\right)(x)+\pi(x)=0$ subject to both the standard value-matching condition $F^{*}(x)=x^{*}-c+F^{*}\left(x_{0}\right)$ (i.e. continuity across the exercise boundary) and the smooth fit principle $F^{* \prime}\left(x^{*}\right)=1$ (i.e. continuous differentiability across the exercise boundary). It is worth pointing out that the proof of Lemma 3.1 actually establishes that the value function (3.4) is differentiable on its domain $\mathbb{R}_{+}$only if the threshold $y$ satisfies the ordinary first order condition (3.8), that is, only if the exercise threshold $y$ is such that it maximizes the auxiliary mapping $u(x)$. 
Given the findings of Lemma 3.1, let us now consider the behavior of the mapping $u^{\prime}(x)$ more thoroughly in order to derive globally valid sufficient conditions guaranteeing both the existence and uniqueness of an optimal threshold $x^{*}$ at which the irreversible harvesting opportunity should be exercised. Ordinary differentiation now yields after a simple algebraic simplification that $u^{\prime}(x)=\psi^{\prime}(x) v(x) /\left(\psi(x)-\psi\left(x_{0}\right)\right)^{2}$, where

$$
v(x)=\left(R_{r} \theta\right)(x)-\left(\psi(x)-\psi\left(x_{0}\right)\right) I(x)-\left(R_{r} \theta\right)\left(x_{0}\right)+c-x_{0},
$$

and the mapping $I: \mathbb{R}_{+} \mapsto \mathbb{R}$ is defined as $I(x)=\left(R_{r} \theta\right)^{\prime}(x) / \psi^{\prime}(x)$. It is now clear that (3.10) can also be rewritten as

$$
v(x)=J(x)-J\left(x_{0}\right)+\psi\left(x_{0}\right)\left(I(x)-I\left(x_{0}\right)\right)+\left(c-x_{0}\right),
$$

where $J(x)=\left(R_{r} \theta\right)(x)-I(x) \psi(x)$. We can now prove the following

Lemma 3.2. Assume that $\lim _{x \downarrow 0} \theta(x) \geq 0>\lim _{x \rightarrow \infty} \theta(x)$, and that there is a threshold $\tilde{x}=\operatorname{argmax}\{\theta(x)\} \in \mathbb{R}_{+}$such that $\theta(x)$ is increasing on $(0, \tilde{x})$ and decreasing on $(\tilde{x}, \infty)$. Then, there is a unique threshold $\hat{x}=\operatorname{argmin}\{I(x)\}=\operatorname{argmax}\{J(x)\}$ satisfying the first order condition

$$
\int_{0}^{\hat{x}} \frac{\psi^{\prime}(y)}{S^{\prime}(y)} \theta^{\prime}(y) d y=0 .
$$

In particular, $\hat{x} \in\left(\tilde{x}, \theta^{-1}(0)\right)$ and $J^{\prime}(x)=-\psi(x) I^{\prime}(x) \gtreqless 0$ when $x \lesseqgtr \hat{x}$.

Proof. See Appendix B.

Lemma 3.2 states a set of typically satisfied conditions under which the auxiliary mapping $I(x)$ attains a unique global minimum so that $J(x)$ attains a unique global maximum on $\mathbb{R}_{+}$. Given the results of Lemma 3.2 and equation (3.10) we can now establish the following key result needed in the subsequent verification of the optimality of the proposed harvesting policy.

Lemma 3.3. Assume that the conditions of Lemma 3.2 are met and that $x_{0}<\hat{x}$. Then, there is a unique exercise threshold $x^{*}=\operatorname{argmax}\{u(x)\}>\hat{x}$ satisfying the first order necessary condition (3.8), and $F^{*}(x)$ satisfies the boundary value problem (3.9). Moreover, $\left((\mathcal{A}-r) F^{*}\right)(x)+\pi(x) \leq 0$ on $\left(x^{*}, \infty\right)$.

Proof. See Appendix C.

Lemma 3.3 states a set of very general and, thus, typically satisfied conditions under which a unique optimal exercise threshold $x^{*}$ maximizing the value of $u(x)$ exists and under which the Markovian functional $F^{*}(x)$ is $r$-superharmonic for the controlled process $X_{t}$ (cf. Øksendal 1998, chapter 10). But unfortunately, this is not yet sufficient for establishing that $F^{*}(x)$ would coincide with the value of the optimal harvesting policy and, therefore, more analysis is needed. Our first set of general sufficient conditions under which we always have this equality (i.e. $V(x)=F^{*}(x)$ ) are now summarized in the following

Theorem 3.4. Assume that the conditions of Lemma 3.2 are met, that $x_{0}<\hat{x}$, and that $F^{*}(x) \geq(x-c)+F^{*}\left(x_{0}\right)$ on $\left(0, x_{0}\right)$. Then, $F^{*}(x)=V(x)$ and the optimal rotation policy is described as follows. If $x \geq x^{*}$, then $\tau_{1}=0, \zeta_{1}=x-x_{0}, \tau_{i+1}=\inf \left\{t \geq \tau_{i}: X_{t}^{\nu} \geq x^{*}\right\}$, and $\zeta_{i+1}=x^{*}-x_{0}, i \geq 1$. If $x<x^{*}$, then $\tau_{i+1}=\inf \left\{t \geq \tau_{i}: X_{t}^{\nu} \geq x^{*}\right\} \quad(\infty=0)$ and $\zeta_{i+1}=x^{*}-x_{0}$, for all $i \geq 0$. 
Proof. See Appendix D.

Theorem 3.4 states a set of sufficient conditions under which the associated Markovian functional $F^{*}(x)$ constitutes the value of the optimal rotation problem (2.3) and under which the optimal rotation threshold is $x^{*}$. Next we characterize the properties of the present value of amenity services in

Theorem 3.5. Assume that the mappings $\mu(x), \sigma(x)$ are continuously differentiable with Lipschitz-continuous derivatives, $\sigma^{\prime}(x)$ satisfies the standard Novikov-condition

$$
E_{x}\left[\exp \left(\frac{1}{2} \int_{0}^{t} \sigma^{\prime 2}\left(X_{s}\right) d s\right)\right]<\infty, \quad(t, x) \in \mathbb{R}_{+}^{2},
$$

the drift $\mu(x)$ is concave, and the flow of revenues $\pi(x)$ is non-decreasing and concave. Then, the expected cumulative present value accrued from amenity services is non-decreasing and concave, that is, $\left(R_{r} \pi\right)^{\prime}(x) \geq 0$ and $\left(R_{r} \pi\right)^{\prime \prime}(x) \leq 0$ for all $x \in \mathbb{R}_{+}$ and increased volatility decreases the expected cumulative present value $\left(R_{r} \pi\right)(x)$. Moreover, the expected value of timber revenues over a single rotation cycle of length $t$

$$
u(t, x)=\mathbf{E}_{x}\left[e^{-r t}\left(X_{t}-c\right)\right]
$$

is increasing and concave in $x$, that is, $u_{x}(t, x) \geq 0$ and $u_{x x}(t, x) \leq 0$ for all $(t, x) \in \mathbb{R}_{+}^{2}$, and the mapping

$$
v(t, x)=\mathbf{E}_{x}\left[e^{-r t}\left(X_{t}-c\right)+\int_{0}^{t} e^{-r s} \pi\left(X_{s}\right) d s\right]
$$

is increasing and concave in $x$, that is, $v_{x}(t, x) \geq 0$ and $v_{x x}(t, x) \leq 0$ for all $(t, x) \in \mathbb{R}_{+}^{2}$. Finally, increased volatility decreases both $u(t, x)$ and $v(t, x)$.

Proof. See Appendix E.

According to Theorem 3.5 under a set of typically satisfied conditions the expected cumulative present value of the revenues accrued from amenity services is concave as a function of the current state $x$ and that the sign of the relationship between volatility and $\left(R_{r} \pi\right)(x)$ is unambiguously negative. Moreover, we also find that the expected revenues accrued over a single rotation cycle are concave as a function of the current state $x$ and, therefore, negatively dependent on the volatility of the process $X_{t}$.

The precise nature of the amenity valuation function - which turns out to be important later on - depends on the nature of amenity services like timber and deer, timber and water, wild life diversity and visual aesthetics which might differ depending on the specific situation (see e.g. Calish et. al 1978)). Therefore, we next characterize under certain set of conditions how the properties of both the expected cumulative value and the expected marginal cumulative value, accrued from amenity services, depend on the precise nature of the monetary valuation of amenities. Moreover, and importantly, we also demonstrate the impact of increased volatility on these factors. First, we present the following

Theorem 3.6. Assume that $\sigma(x)=\sigma x$, where $\sigma>0$ is a known constant, and that the mapping $\mu(x)$ is concave and continuously differentiable with Lipschitz-continuous derivatives. Assume also that $\mu^{\prime}(x)$ is convex, that the flow of revenues $\pi(x)$ is nonincreasing and convex, and that $\pi^{\prime}(x)$ is concave. Then, 
(i) the expected cumulative present value accrued from amenity services $\left(R_{r} \pi\right)(x)$ is non-increasing and convex, and increased volatility increases its value $\left(R_{r} \pi\right)(x)$,

(ii) the marginal expected cumulative present value accrued from amenity services $\left(R_{r} \pi\right)^{\prime}(x)$ is non-decreasing and concave, and increased volatility decreases its value. Moreover, increased volatility decreases the value $\left(R_{r} \pi\right)(x)-\left(R_{r} \pi\right)\left(x_{0}\right)$ for all $x \in\left[x_{0}, \infty\right)$.

Proof. See Appendix F.

Theorem 3.6 states a set of conditions under which increased volatility unambiguously increases the expected cumulative present value of the returns accrued from amenity services but simultaneously decreases its marginal value. This result is of interest since it demonstrates that even when the sign of the relationship between increased volatility and the expected cumulative revenues may be positive, the impact on the difference $\left(R_{r} \pi\right)(x)-\left(R_{r} \pi\right)\left(x_{0}\right)$ determining the nature of the optimal ongoing rotation policy, may be negative. Thus, the properties of the optimal ongoing rotation policy may be opposite to the ones of an optimal single rotation strategy. This result emphasizes the impact of the sequentiality of the ongoing rotation policies on their comparative static properties. Since the opportunity to harvest later in the future is lost in the single rotation case immediately after the irreversible decision has been made, the decision maker cannot pursue a policy where the value process would be sustained at a level where the flow of returns accrued from amenity services is high. Since the decision maker can, however, implement such a policy in the ongoing rotation case, we immediately observe that the impact of increased volatility on the optimal policy is very different in cases where volatility affects the expected cumulative present value of the returns accrued from amenity services in an opposite way it affects its marginal value. A second associated result is now established in the following

Theorem 3.7. Assume that $\sigma(x)=\sigma x$, where $\sigma>0$ is a known constant, and that the mapping $\mu(x)$ is concave and continuously differentiable with Lipschitz-continuous derivatives. Assume also that $\mu^{\prime}(x)$ is convex, that the flow of revenues $\pi(x)$ is nondecreasing and concave, and that $\pi^{\prime}(x)$ is convex. Then,

(i) the expected cumulative present value accrued from amenity services $\left(R_{r} \pi\right)(x)$ is non-decreasing and concave, and increased volatility decreases its value $\left(R_{r} \pi\right)(x)$,

(ii) the marginal expected cumulative present value accrued from amenity services $\left(R_{r} \pi\right)^{\prime}(x)$ is non-increasing and convex, and increased volatility increases its value. Moreover, increased volatility increases the value $\left(R_{r} \pi\right)(x)-\left(R_{r} \pi\right)\left(x_{0}\right)$ for all $x \in\left[x_{0}, \infty\right)$.

Proof. The proof is analogous with the proof of Theorem 3.6.

In contrast to Theorem 3.6, Theorem 3.7 states a set of conditions under which increased volatility unambiguously decreases the expected cumulative present value of the returns accrued from amenity services but simultaneously increases its marginal value. The interpretation of this result is analogous to Theorem 3.6. Finally, in the ongoing rotation framework with amenity valuation we show the following. 
Theorem 3.8. If the value function $F(x)$ is concave, then increased volatility decreases the value of the optimal rotation policy.

Proof. See Appendix G.

Notice, however, that Theorem 3.8 does not characterize the relationship between volatility and the optimal rotation threshold $x^{*}$. As we will see in an explicit example later, the relationship between volatility and the optimal rotation threshold $x^{*}$ depends heavily on nature of the amenity valuation function and the boundary behavior of the diffusion process modelling the value of the forest stand.

\section{Wicksellian stochastic single rotation problem with amenity valuation}

The analysis of the previous section has been devoted to the Faustmannian ongoing rotation problem with amenity valuation. A closely related problem arising in the literature of optimal forest rotation is the so-called Wicksellian single rotation problem.

In this section we explicitly characterize in the presence of amenity valuation an associated Wicksellian single rotation problem in terms of optimal exercise threshold, optimal rotation date and the resulting value function and compare the value function with the one from the Faustmannian ongoing rotation problem. The objective of the forest owner is now to determine the rotation date $\tau$ for which the maximum

$$
\hat{V}(x)=\sup _{\tau<\infty} \mathbf{E}_{x}\left[e^{-r \tau}\left(X_{\tau}-c\right)+\int_{0}^{\tau} e^{-r s} \pi\left(X_{s}\right) d s\right]
$$

is attained. The strong Markov property of diffusions now implies that problem (4.1) can be re-expressed as

$$
\hat{V}(x)=\left(R_{r} \pi\right)(x)+\sup _{\tau<\infty} \mathbf{E}_{x}\left[e^{-r \tau}\left(X_{\tau}-c-\left(R_{r} \pi\right)\left(X_{\tau}\right)\right)\right] .
$$

This demonstrates how the value of the optimal policy can be decomposed into the returns accrued from keeping the forest unharvested (the monetary value of the return accrued from amenity services) and the expected returns accrued from exercising the harvesting opportunity later in the future. Our main result on this problem is summarized in the following

Theorem 4.1. Assume that the mapping $\theta(x)=\pi(x)+\mu(x)-r(x-c)$, measuring the expected growth rate of the total value of a forest stand, satisfies the condition $\theta(x) \gtreqless 0$ for $x \lesseqgtr \hat{y}$, where $\hat{y} \in \mathbb{R}_{+}$is a known threshold. Then, there is a unique optimal exercise threshold $x_{W}^{*}=\operatorname{argmax}\left\{\frac{x-c-\left(R_{r} \pi\right)(x)}{\psi(x)}\right\}=\operatorname{argmin}\left\{\frac{\left(R_{r} \theta\right)(x)}{\psi(x)}\right\}$ satisfying the ordinary first order necessary condition

$$
\int_{0}^{x_{W}^{*}} \psi(y) \theta(y) m^{\prime}(y) d y=0
$$


Moreover, $\tau_{W}^{*}=\inf \left\{t \geq 0: X(t) \geq x_{W}^{*}\right\}$ is the optimal rotation date and the value function reads as

$$
V(x)= \begin{cases}x-c, & x \geq x_{W}^{*} \\ x-c+\left(R_{r} \theta\right)(x)-\left(R_{r} \theta\right)\left(x_{W}^{*}\right) \frac{\psi(x)}{\psi\left(x_{W}^{*}\right)}, & x<x_{W}^{*} .\end{cases}
$$

Proof. The alleged result follows directly from part (A) of Theorem 4 in Alvarez 2001d.

Theorem 4.1 states a set of sufficient conditions under which the Wicksellian single rotation problem can be solved explicitly. It is worth emphasizing that the conditions of Theorem 4.1 are significantly weaker than the conditions of Theorem 3.4 for the Faustmannian problem. Unfortunately, it is not easy (if possible at all) to extend the results of Theorem 4.1 to the ongoing rotation case, although we know that these values are closely related to each other. An important consequence of our Theorem 3.4 is now presented in the following

Corollary 4.2. Assume that the conditions of Theorem 3.4 are met. Then, $V(x) \geq$ $\hat{V}(x)$ for all $x \in \mathbb{R}_{+}$.

Proof. See Appendix H.

Corollary 4.2 proves that the value of the Faustmannian ongoing rotation problem dominates the value of the Wicksellian single rotation problem in the presence of amenity valuation as well.

\section{Some Numerical Illustrations}

After having characterized the value of both the Faustmannian ongoing rotation problem and the Wicksellian single rotation problem in the presence of amenity valuation, we now explicitly illustrate our results both in deterministic and stochastic models based on a logistic growth of the forest value. More precisely, we focus the role of amenity valuation function, interest rate and growth and volatility of forest value under much more general assumptions than in the earlier literature about the relationship between the forest value and the monetary value of amenity services.

\subsection{Deterministic Logistic Growth}

We now assume that the dynamics of the controlled process modelling the value of the forest stand read as

$$
X_{t}^{\prime}=\mu X_{t}\left(1-\gamma X_{t}\right), \quad X_{0}=x,
$$

where $\mu$ denoting the intrinsic growth rate at low densities and $\gamma^{-1}$ denoting the carrying capacity of the value of the forest stand are exogenously given constants. The amenity revenues are, in turn, assumed to be of the form $\pi(x)=a x^{b}$, where $a>0$ and $b \in \mathbb{R}$ are 
exogenously given constants. Consequently, the auxiliary mapping $\theta(x)$, characterized in section 2 , now reads as

$$
\theta(x)=a x^{b}+\mu x(1-\gamma x)-r(x-c) .
$$

Our assumptions imply that the mapping $\theta(x)$ is strictly concave and attains a unique maximum at the point $\tilde{x}$ satisfying the ordinary first order necessary condition

$$
a b \tilde{x}^{b-1}+\mu-r=2 \mu \gamma \tilde{x} .
$$

It is now a simple exercise in ordinary analysis to establish that for any $f \in C_{b}((0,1 / \gamma])$ $\left(C_{b}(A)\right.$ denotes the collection of continuous and bounded mappings on $\left.A\right)$ and $x \in$ $(0,1 / \gamma)$ we have that

$$
\left(R_{r} f\right)(x)=\frac{1}{\mu}\left(\frac{x}{1-\gamma x}\right)^{r / \mu} \int_{x}^{1 / \gamma} f(y) y^{-r / \mu-1}(1-\gamma y)^{r / \mu-1} d y .
$$

Thus, the cumulative present value of the future revenues accrued from amenity services can be expressed as

$$
\left(R_{r} \pi\right)(x)=\frac{a}{\mu}\left(\frac{x}{1-\gamma x}\right)^{r / \mu} \int_{x}^{1 / \gamma} y^{b-r / \mu-1}(1-\gamma y)^{r / \mu-1} d y .
$$

For example, if $r=\mu$ and $b \neq 1$ then

$$
\left(R_{r} \pi\right)(x)=\frac{a}{\mu}\left(\frac{x}{1-\gamma x}\right) \frac{1}{b-1}\left[\gamma^{1-b}-x^{b-1}\right] .
$$

It is now clear that in the present case, the associated Wicksellian rotation problem reads as

$$
\hat{V}(x)=\sup _{t \geq 0}\left[\int_{0}^{t} e^{-r s} a X_{s}^{b} d s+e^{-r t}\left(X_{t}-c\right)\right]=(x-c)+\sup _{t \geq 0} \int_{0}^{t} e^{-r s} \theta\left(X_{s}\right) d s .
$$

Since the conditions of our Theorem 4.1 are now satisfied, we find that the optimal (Wicksell) threshold $x_{W}^{*}$ at which the forest should optimally be rotated constitutes the unique interior root of the ordinary first order condition $\theta\left(x_{W}^{*}\right)=0$, that is, of the condition

$$
a x_{W}^{*}{ }^{b}+\mu x_{W}^{*}\left(1-\gamma x_{W}^{*}\right)=r\left(x_{W}^{*}-c\right) .
$$

On the other hand, the optimal (Faustmann) threshold $x^{*}$ is the unique interior root of the ordinary first order condition

$$
\left(\frac{x^{*}}{1-\gamma x^{*}}\right)^{r / \mu}\left[\theta\left(x^{*}\right)-r\left(R_{r} \pi\right)\left(x_{0}\right)\right]=\left(\frac{x_{0}}{1-\gamma x_{0}}\right)^{r / \mu}\left[\theta\left(x^{*}\right)-r\left(R_{r} \theta\right)\left(x^{*}\right)\right] .
$$

Unfortunately, solving the optimal thresholds $x_{W}^{*}$ and $x^{*}$ explicitly from these optimality conditions is typically impossible. Therefore, we illustrate numerically our results in the following under the assumptions that $a=1 \%, \mu=r=4 \%, \gamma=0.2, c=2$, and $x_{0}=1$. 


\begin{tabular}{|c|c|c|c|c|}
\hline$b$ & -1.1 & -0.5 & 0.5 & 1.1 \\
\hline$x^{*}$ & 2.93 & 2.95 & 3.10 & 3.40 \\
$x_{W}^{*}$ & 3.22 & 3.27 & 3.51 & 3.96 \\
$x_{W}^{*}-x^{*}$ & 0.29 & 0.32 & 0.41 & 0.56 \\
\hline
\end{tabular}

Table 1

The results of Table 1 can be characterized as follows. First, the Faustmannian threshold value, $x^{*}$, falls short of the Wicksellian one, $x_{W}^{*}$, independent of the precise specification of the amenity valuation function $\pi(x)$. This is natural because it means that the optimal rotation age in the Faustmann case is shorter than in the Wicksell case for natural reasons, elaborated in the literature. Second, the threshold difference will increase, when the marginal amenity valuation of the forest stand becomes higher. This is simply because an increasing amenity valuation of the forest stand lengthens the optimal threshold more in the Faustmannian case than in the Wicksellian case.

Next, we illustrate numerically our results in the case when $a=1 \%, \mu=r=8 \%$, $\gamma=0.2, c=2$, and $x_{0}=1$.

\begin{tabular}{|c|c|c|c|c|}
\hline$b$ & -1.1 & -0.5 & 0.5 & 1.1 \\
\hline$x^{*}$ & 2.96 & 2.98 & 3.05 & 3.18 \\
$x_{W}^{*}$ & 3.19 & 3.22 & 3.34 & 3.54 \\
$x_{W}^{*}-x^{*}$ & 0.23 & 0.24 & 0.29 & 0.35 \\
\hline
\end{tabular}

Table 2

The numerics of Table 2 provide an answer to the following question: What is the relationship between the Faustmannian and Wicksellian rotation thresholds when the interest rate (= the opportunity cost of not harvesting) will be higher than in Table 1. Naturally, the result presented earlier holds; there is still a difference, but a smaller one, i.e. in the case of higher interest rate, the difference between the thresholds $x^{*}$ and $x_{W}^{*}$, will be smaller.

In order to illustrate the role of the flow of returns accrued from amenity services, measured by parameter $a$, we illustrate in Table 3 the optimal policies in the case when $a=5 \%, \mu=r=4 \%, \gamma=0.2, c=2$, and $x_{0}=1$.

\begin{tabular}{|c|c|c|c|c|c|}
\hline$b$ & -1.1 & -0.5 & 0.5 & 0.8 & 1.1 \\
\hline$x^{*}$ & 2.65 & 2.77 & 3.57 & 4.46 & 5 \\
$x_{W}^{*}$ & 3.41 & 3.64 & 4.88 & 5 & 5 \\
$x_{W}^{*}-x^{*}$ & 0.76 & 0.87 & 1.31 & 0.54 & 0 \\
\hline
\end{tabular}

Table 3

A higher flow of returns increases the difference between the threshold values if the elasticity of the cash flow accrued from amenity services, measured by parameter $b$, is low enough. But when the elasticity increases then the difference between the threshold values starts to decrease and finally we end up with a corner solution in both cases. In fact, a sufficiently high increase in the elasticity shifts the optimal thresholds towards the carrying capacity of the value of the forest stand $\gamma^{-1}$ thus implying that harvesting is never optimal independent of the time horizon as the monetary value of amenity services dominates the returns from harvesting at all states. 


\subsection{Stochastic Logistic Growth}

In order to consider the impact of stochastic fluctuations of the value of the forest stand on the optimal rotation policy and its value, we now assume that the controlled diffusion evolves according to a stochastic logistic growth model described by the stochastic differential equation

$$
d X_{t}=\mu X_{t}\left(1-\gamma X_{t}\right) d t+\sigma X_{t} d W_{t}, \quad X_{0}=x,
$$

where $\mu, \gamma$, and $\sigma$ are exogenously given positive constants. In order to get an explicit solution, we also assume that $\pi(x)=\bar{\pi} / x$. Applying now Itô's theorem to the mapping $Y_{t}=1 / X_{t}$ yields

$$
d Y_{t}=\left(\mu \gamma-\left(\mu-\sigma^{2}\right) Y_{t}\right) d t-\sigma Y_{t} d W_{t}, \quad Y_{0}=\frac{1}{x} .
$$

Consequently, we find that

$$
E_{x}\left[\frac{1}{X_{t}}\right]=\frac{\mu \gamma}{\mu-\sigma^{2}}+e^{-\left(\mu-\sigma^{2}\right) t}\left[\frac{1}{x}-\frac{\mu \gamma}{\mu-\sigma^{2}}\right]
$$

which, provided that the absence of speculative bubbles condition $r+\mu>\sigma^{2}$ is satisfied, implies

$$
\left(R_{r} \pi\right)(x)=\frac{\bar{\pi}}{\left(r+\mu-\sigma^{2}\right) x}+\frac{\mu \gamma \bar{\pi}}{r\left(r+\mu-\sigma^{2}\right)} .
$$

It is worth noticing that

$$
\frac{\partial\left(R_{r} \pi\right)(x)}{\partial \sigma}=\left[\frac{\bar{\pi}}{x}+\frac{\mu \gamma \bar{\pi}}{r}\right] \frac{2 \sigma}{\left(r+\mu-\sigma^{2}\right)^{2}}>0
$$

and

$$
\frac{\partial\left(R_{r} \pi\right)^{\prime}(x)}{\partial \sigma}=-\frac{\bar{\pi}}{x^{2}} \frac{2 \sigma}{\left(r+\mu-\sigma^{2}\right)^{2}}<0 .
$$

This means, as was proved in Theorem 3.6, that increased volatility increases the expected cumulative present value of the returns accrued from amenity services, but simultaneously decreases its marginal value. Moreover, in line with the findings of Theorem 3.6 we also find that increased volatility decreases the difference $\left(R_{r} \pi\right)(x)-\left(R_{r} \pi\right)\left(x_{0}\right)$ and, therefore, increases the incentives to harvest.

It is clear from the analysis above that the auxiliary mapping $u(x)$ now reads as

$$
u(x)=\frac{\left(r+\mu-\sigma^{2}\right) x_{0} x(x-c)+\bar{\pi}\left(x-x_{0}\right)}{\left(r+\mu-\sigma^{2}\right) x_{0} x\left(\psi(x)-\psi\left(x_{0}\right)\right)},
$$

where $\psi(x)=x^{\delta} M\left(\delta, 2 \delta+\frac{2 \mu}{\sigma^{2}}, \frac{2 \mu \gamma}{\sigma^{2}} x\right), \delta=\frac{1}{2}-\frac{\mu}{\sigma^{2}}+\sqrt{\left(\frac{1}{2}-\frac{\mu}{\sigma^{2}}\right)^{2}+\frac{2 r}{\sigma^{2}}}$, and $M$ is the confluent hypergeometric function (cf. Alvarez and Shepp 1998 and Willasen 1998). In this example, the optimal Wicksellian threshold $x_{W}^{*}$ is the threshold maximizing the functional

$$
u_{W}(x)=\frac{r\left(r+\mu-\sigma^{2}\right) x(x-c)-r \bar{\pi}+\mu \gamma \bar{\pi} x}{r\left(r+\mu-\sigma^{2}\right) x^{1+\delta} M\left(\delta, 2 \delta+\frac{2 \mu}{\sigma^{2}}, \frac{2 \mu \gamma}{\sigma^{2}} x\right)}
$$


The optimal rotation threshold $x^{*}$ and the Wicksellian threshold $x_{W}^{*}$ are illustrated as functions of the volatility coefficient $\sigma$ in the following table in the case when $\gamma=0.2$, $r=\mu=4 \%, c=2, \bar{\pi}=1$ and $x_{0}=1$.

\begin{tabular}{|c|c|c|c|c|c|}
\hline$\sigma$ & 0.05 & 0.1 & 0.15 & 0.2 & 0.25 \\
\hline$x^{*}$ & 1.33 & 1.32 & 1.29 & 1.23 & 1.15 \\
$x_{W}^{*}$ & 7.06 & 8.29 & 10.05 & 13.02 & 21.56 \\
$x_{W}^{*}-x^{*}$ & 5.73 & 6.97 & 8.76 & 11.79 & 20.41 \\
\hline
\end{tabular}

Table 4

According to the findings presented in Table 4, higher volatility increases the Wicksellian threshold while, interestingly, decreases the Faustmannian threshold. This can be interpreted as follows. As we established in (5.7) increased volatility increases the expected cumulative revenues accrued from amenity services and, therefore, increases the incentives to postpone the harvesting decision in the Wicksellian case. In contrast, in (5.8) we found that increased volatility decreases the marginal value of the expected cumulative revenues accrued from amenity services and, therefore, increases the incentives to harvest by decreasing the expected marginal returns associated to the amenity services. We would like to point out that this new finding is the main qualitative difference between the Wicksellian and Faustmannian rotation policies in the presence of amenity services showing that the precise nature of the monetary value of amenities has an important qualitative effect as well.

\section{Concluding Remarks}

This paper has provided a new and more general approach to study the optimal rotation policy with amenity valuation under uncertainty when the underlying dynamics of the forest value is described by a linear and time homogenous diffusion process. In the small existing literature the authors have assumed different stochastic formulations for forest values and amenity values without an explicit justification. We have first postulated stochastic forest value and assumed that monetary value of amenities is a continuous and non-negative function of the forest value thus emphasizing the trade-off between timber revenues and amenity values. Second, and importantly, instead of using dynamic programming, we have derived an associated functional form from which the optimal rotation threshold and its value can be explicitly solved in terms of exogenous parameters by solely relying on ordinary non-linear programming techniques. Third, we have characterized under certain set of conditions how the properties of both the expected cumulative present value and the expected marginal cumulative present value, accrued form amenity services, depend on the precise nature of the amenity valuation function and how the volatility of the forest value affects these concepts. Finally, we have illustrated our results numerically both in deterministic and stochastic models based on logistic growth with the emphasis on the role of the properties of amenity valuation function, interest rate and both the growth and volatility of forest value for the determination of Wicksellian and Faustmanian thresholds.

According to our numerical results the difference between the Wicksellian and the Faustmanian threshold values is positively related to the flow of returns provided that 
the elasticity of the cash flow accrued from amenity services is low enough. When the elasticity increases sufficiently, then the difference between the thresholds decreases and finally ends up to a corner solution in both cases. Under certain specification of the amenity valuation function and the nature of the growth rate of the forest value, a higher volatility was shown to increase the Wicksellian threshold while it simultaneously decreases the Faustmannian threshold. This is because increased volatility increases the expected cumulative revenues accrued from amenity services and, therefore, increases the incentives to postpone the harvesting decision in the Wicksellian case while decreases the marginal value of the expected cumulative revenues accrued from amenity services, which is relevant for the Faustmannian threshold and, therefore, decreases the incentives to postpone the harvesting decision in the Faustmannian case.

Acknowledgements: The research of Luis H. R. Alvarez has been supported by the Foundation for the Promotion of the Actuarial Profession and the Yrjö Jahnsson Foundation. Erkki Koskela thanks the Research Unit of Economic Structures and Growth (RUESG) in the University of Helsinki and the Yrjö Jahnsson Foundation for financial support. 


\section{References}

[1] Alvarez, L. H. R. Singular stochastic control, linear diffusions, and optimal stopping: A class of solvable problems, 2001a, SIAM Journal on Control and Optimization, 39, 1697 - 1710.

[2] Alvarez, L. H. R. Impulse and Singular Control, Linear Diffusions, and Intervention Costs: A Class of Solvable Problems, 2001b, Turku School of Economics and Business Administration, mimeo.

[3] Alvarez, L. H. R. A Class of Solvable Impulse Control Problems, 2001c, Turku School of Economics and Business Administration, mimeo.

[4] Alvarez, L. H. R. Reward functionals, salvage values, and optimal stopping, 2001d, Mathematical Methods of Operations Research, 54, 315-337.

[5] Alvarez, L. H. R. and Shepp, L. A. Optimal harvesting of stochastically fluctuating populations, 1998, Journal of Mathematical Biology, vol. 37, 155 - 177.

[6] Binkley, C. Timber Supply from Private Industrial Forests, School of Forestry and Environmental Studies, Bulletin No. 92, Yale University, 1982.

[7] Borodin, A. and Salminen, P. Handbook on Brownian motion - Facts and formulae, 1996, Birkhauser, Basel.

[8] Bowes, M.D. and Krutilla, J.V. Multiple-use management of public forestlands, in Kneese, A.V. and Sweeney, J.L. (eds): Handbook of Natural Resource and Energy Economics, Vol. II, 1985, 531-569, North-Holland, Amsterdam.

[9] Brekke, K. A. and Øksendal, B. A verification theorem for combined stochastic control and impulse control, 1996, Stochastic Analysis and Related Topics, VI, 211-220, Birkhäuser, Boston.

[10] Brekke, K. A. and Øksendal, B. Optimal switching in an economic activity under uncertainty, 1994, SIAM Journal on Control and Optimization, 32, 1021 - 1036.

[11] Bulte, E., van Soest, D. P., van Kooten, G. C., and Schipper, R. A. Forest conservation in Costa Rica when nonuse benefits are uncertain but rising, 2002, American Journal of Agricultural Economics, 84, 150-160.

[12] Calish, S., Fight, R.D., and Teeguarden, D. E. How Do Nontimber Values Affect Douglas-fir Rotations, 1978, Journal of Forestry, 76, 217-221.

[13] Conrad, J. M. On the option value of old-growth forest, 1997, Ecological Economics, 22, 97-102.

[14] Conrad, J. M. Wilderness: Options to preserve, extract, or develop, 2000, Resource and Energy Economics, 22, 205-219.

[15] Hartman, R. The harvesting decision when a standing forest has value, 1976, Economic Inquiry, 14, 52-58.

[16] Karlin, S. and Taylor, H. A second course in stochastic processes, 1981, Academic Press, Orlando.

[17] Koskela, E. and Ollikainen, M. Forest taxation and rotation age under private amenity valuation: new results, 2001, Journal of Environmental Economics and Management, 42, $374-384$. 
[18] Koskela, E. and Ollikainen, M. Optimal forest taxation under private and social amenity valuation, 2002, Forest Science, forthcoming.

[19] Kuuluvainen, J. and Tahvonen, O. Testing the forest rotation model: evidence from panel data, 1999, Forest Science, 45, 539-551.

[20] Øksendal, B. Stochastic differential equations: An introduction with applications, (Fifth Edition) 1998, Springer, Berlin.

[21] Øksendal, B. Stochastic control problems where small intervention costs have big effects, 1999, Applied mathematics \& Optimization, 40, 355-375.

[22] Reed, W. J. Optimal Harvesting Models in Forest Management - A Survey, 1986, Natural Resource Modeling, 1, 55-79.

[23] Reed, W. J. The decision to conserve or harvest old-growth forest, 1993, Ecological Economics, 8, 45-69.

[24] Reed, W. J. and Ye, J. J. The role of stochastic monotonicity in the decision to conserve or harvest old-growth forest, 1994, Natural Resource Modelling, 8, 47-79.

[25] Snyder, D.L. and Bhattacharyya, R. A More General Dynamic Economic Model of the Optimal Rotation of Multiple-Use Forests, 1990, Journal of Environmental Economics and Management, 18, 168-175.

[26] Strang, W. J. On the optimal forest harvesting decision, 1983, Economic Inquiry, 21, $756-783$.

[27] Wear, D.N. and Parks, P.J. The Economics of Timber Supply: An Analytical Synthesis of Modeling Approaches, 1994, Natural Resource Modeling, 8, 199-223.

[28] Willassen, Y. The stochastic rotation problem: A generalization of Faustmann's formula to stochastic forest growth, 1998, Journal of Economic Dynamics and Control, 22, 573-596. 


\section{A Proof of Lemma 3.1}

Proof. It is clear from the definition (3.7) that $F^{*}(x)$ is twice continuously differentiable on $\mathbb{R}_{+} \backslash\left\{x^{*}\right\}$. Thus, it is sufficient to consider the behavior of $F^{*}(x)$ and $F^{* \prime}(x)$ on the exercise boundary $x^{*}$. The continuity of $F^{*}(x)$ is a direct consequence of the continuity of $F(x)$ for any admissible harvesting threshold $y$. Standard differentiation now yields that

$$
F^{* \prime}(x)= \begin{cases}1 & x \geq x^{*} \\ 1+\left(R_{r} \theta\right)^{\prime}(x)+u\left(x^{*}\right) \psi^{\prime}(x) & x<x^{*}\end{cases}
$$

Letting $x \uparrow x^{*}$ and invoking the necessary condition (3.8) then proves that $F^{*}(x)$ is continuously differentiable on $\mathbb{R}_{+}$. Finally, since $\left(R_{r} \theta\right)(x)=\left(R_{r} \pi\right)(x)+\left(R_{r} \rho\right)(x)$ satisfies the ordinary differential equation $\left((\mathcal{A}-r)\left(R_{r} \theta\right)\right)(x)+\theta(x)=0$, we find that $F^{*}(x)$ is a solution of the boundary value problem (3.9), thus completing the proof.

\section{B Proof of Lemma 3.2}

Proof. Since $J^{\prime}(x)=-\psi(x) I^{\prime}(x)$ and the increasing fundamental solution $\psi(x)$ is positive, we find that $J(x)$ is increasing on the set where $I(x)$ is decreasing and vice versa so that it is enough to establish the alleged result only for one of these mappings. Consider now the mapping $I(x)$. Since $\left((\mathcal{A}-r)\left(R_{r} \theta\right)\right)(x)+\theta(x)=0$ and $((\mathcal{A}-r) \psi)(x)=0$, we find by ordinary differentiation of $I(x)$ that

$$
I^{\prime}(x)=\frac{2 S^{\prime}(x)}{\sigma^{2}(x) \psi^{\prime 2}(x)}\left[r \int_{0}^{x} \psi(y) \theta(y) m^{\prime}(y) d y-\theta(x) \frac{\psi^{\prime}(x)}{S^{\prime}(x)}\right] .
$$

However, since 0 was assumed to be unattainable, we know that (cf. Borodin and Salminen 1996, p. 18)

$$
\frac{\psi^{\prime}(x)}{S^{\prime}(x)}=r \int_{0}^{x} \psi(y) m^{\prime}(y) d y
$$

implying that $I^{\prime}(x)$ can be rewritten as

$$
I^{\prime}(x)=\frac{2 r S^{\prime}(x)}{\sigma^{2}(x) \psi^{\prime 2}(x)} \int_{0}^{x} \psi(y)(\theta(y)-\theta(x)) m^{\prime}(y) d y=-\frac{2 S^{\prime}(x)}{\sigma^{2}(x) \psi^{\prime 2}(x)} \int_{0}^{x} \frac{\psi^{\prime}(y)}{S^{\prime}(y)} \theta^{\prime}(y) d y .
$$

Define now the functional $G: \mathbb{R}_{+} \mapsto \mathbb{R}$ as

$$
G(x)=r \int_{0}^{x} \psi(y) \theta(y) m^{\prime}(y) d y-\theta(x) \frac{\psi^{\prime}(x)}{S^{\prime}(x)} .
$$

It is now clear that our monotonicity assumptions on the mapping $\theta(x)$ imply that the equation $\theta(x)=0$ has a unique root $\theta^{-1}(0)>\tilde{x}$ and that $\theta(x)>0$ on $x \in\left(0, \theta^{-1}(0)\right)$. Thus, $\lim _{x \downarrow 0} G(x) \leq 0$,

$$
G(\tilde{x}) \leq r \theta(\tilde{x}) \int_{0}^{\tilde{x}} \psi(y) m^{\prime}(y) d y-\theta(\tilde{x}) \frac{\psi^{\prime}(\tilde{x})}{S^{\prime}(\tilde{x})}=-\theta(\tilde{x}) \frac{\psi^{\prime}(0)}{S^{\prime}(0)} \leq 0,
$$

and

$$
G\left(\theta^{-1}(0)\right)=r \int_{0}^{\theta^{-1}(0)} \psi(y) \theta(y) m^{\prime}(y) d y>0 .
$$


These findings prove that equation $G(x)=0$ has a root $\hat{x} \in\left(\tilde{x}, \theta^{-1}(0)\right)$ and, therefore, that

$$
\int_{0}^{\hat{x}} \frac{\psi^{\prime}(y)}{S^{\prime}(y)} \theta^{\prime}(y) d y=0 .
$$

However, since $G(x)$ is increasing (decreasing) on the set where $\theta(x)$ is decreasing (increasing) we find that this root is indeed unique and that $G(x) \lesseqgtr 0$ when $x \lesseqgtr \hat{x}$ (cf.

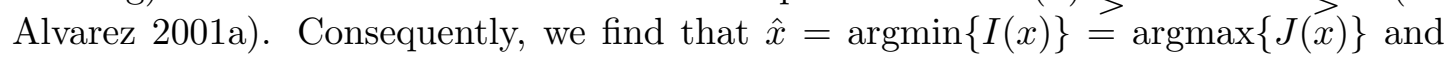
our proof is complete.

\section{Proof of Lemma 3.3}

Proof. Utilizing (3.10) gives

$$
v^{\prime}(x)=-\left(\psi(x)-\psi\left(x_{0}\right)\right) I^{\prime}(x) .
$$

Therefore, Lemma 3.2 and the monotonicity of the increasing fundamental solution $\psi(x)$ imply that $v(x)$ is decreasing on $\left(0, x_{0}\right) \cup(\hat{x}, \infty)$ and increasing on $\left(x_{0}, \hat{x}\right)$. However, since $v\left(x_{0}\right)=\left(c-x_{0}\right)>0$ we find that $v(x)>0$ on $(0, \hat{x})$. Hence, if equation $v(x)=0$ has a root, it must be on $(\hat{x}, \infty)$. Assume now that $x>\hat{x}$. Then it is a simple exercise in ordinary analysis to establish that

$$
\begin{aligned}
v(x) & =v(\hat{x})+(I(\hat{x})-I(x))\left(\psi(\hat{x})-\psi\left(x_{0}\right)\right)+\int_{\hat{x}}^{x} \psi^{\prime}(y)(I(y)-I(x)) d y \\
& =v(\hat{x})+(I(\hat{x})-I(x))\left(\psi(\hat{x})-\psi\left(x_{0}\right)\right)+(I(\xi)-I(x))(\psi(x)-\psi(\hat{x})),
\end{aligned}
$$

where $\xi \in(\hat{x}, x)$. Now letting $x \rightarrow \infty$ yields that $\lim _{x \rightarrow \infty} v(x)=-\infty$, since $\psi(x)$ is monotonically increasing and satisfies the condition $\lim _{x \rightarrow \infty} \psi(x)=\infty$. Thus, the continuous mapping $v(x)$ changes sign and, therefore, has at least one root $x^{*}$ on the set $(\hat{x}, \infty)$. Since $v(x)$ is monotonic on $(\hat{x}, \infty)$ we find that this root is unique. Moreover, $v(x) \gtreqless 0$ on $x \lesseqgtr x^{*}$ proving that $x^{*}=\operatorname{argmax}\{u(x)\}$. The result that $F^{*} \in C^{1}\left(\mathbb{R}_{+}\right) \cap$ $C^{2}\left(\mathbb{R}_{+} \backslash\left\{x^{*}\right\}\right)$ and satisfies the boundary value problem (3.9) follows from Lemma 3.1. It remains to establish that $F^{*}(x)$ satisfies the variational inequality $\left((\mathcal{A}-r) F^{*}\right)(x)+$ $\pi(x) \leq 0$ on $\left(x^{*}, \infty\right)$. To prove that this is indeed the case, we first notice that for all $x \in\left(x^{*}, \infty\right)$ we have

$$
\left((\mathcal{A}-r) F^{*}\right)(x)+\pi(x)=\theta(x)-r J\left(x_{0}\right)+r \psi\left(x_{0}\right)\left(I\left(x^{*}\right)-I\left(x_{0}\right)\right)+r\left(c-x_{0}\right) .
$$

Since $J\left(x_{0}\right)-\psi\left(x_{0}\right)\left(I\left(x^{*}\right)-I\left(x_{0}\right)\right)-\left(c-x_{0}\right)=J\left(x^{*}\right)$ (follows from the optimality condition $\left.v\left(x^{*}\right)=0\right)$, we find that for all $x \in\left(x^{*}, \infty\right)$ we have $\left((\mathcal{A}-r) F^{*}\right)(x)+\pi(x)=$ $\theta(x)-r J\left(x^{*}\right)$. However, since

$$
I^{\prime}(x)=\frac{d}{d x}\left[\frac{\left(R_{r} \theta\right)^{\prime}(x)}{\psi^{\prime}(x)}\right]=\frac{2}{\sigma^{2}(x) \psi^{\prime}(x)}[r J(x)-\theta(x)],
$$

we find by invoking the monotonicity of the mappings $I(x)$ and $J(x)$ on $\left(x^{*}, \infty\right)$ that $\left((\mathcal{A}-r) F^{*}\right)(x)+\pi(x) \leq r\left(J(x)-J\left(x^{*}\right)\right) \leq 0$, thus completing the proof of Lemma 3.3 . 


\section{Proof of Theorem 3.4}

Proof. As was established in Lemma 3.3, given the conditions of our theorem, the value $F^{*}(x)$ is stochastically of class $C^{2}$ and satisfies the variational inequality $((\mathcal{A}-$ $\left.r) F^{*}\right)(x)+\pi(x)=0$ on $\mathbb{R}_{+}$. Similarly, since the state-space of $X_{t}^{\nu}$ is bounded under the proposed policy, we find that

$$
\lim _{t \rightarrow \infty} \mathbf{E}_{x}\left[e^{-r\left(t \wedge \tau^{\nu}(0)\right)} F^{*}\left(X_{t \wedge \tau^{\nu}(0)}^{\nu}\right)\right]=0
$$

for all $x \in \mathbb{R}_{+}$. Consider now the mapping $\Delta: \mathbb{R}_{+} \mapsto \mathbb{R}$ defined as

$$
\Delta(x)=F^{*}(x)-(x-c)-F^{*}\left(x_{0}\right)= \begin{cases}0 & x \geq x^{*} \\ \left(\psi(x)-\psi\left(x_{0}\right)\right)\left[u\left(x^{*}\right)-u(x)\right] & x<x^{*}\end{cases}
$$

It is clear from this expression that $\Delta(x) \geq 0$ as long as $x \geq x_{0}$. Thus, our assumption $F^{*}(x) \geq(x-c)+F^{*}\left(x_{0}\right)$ on $\left(0, x_{0}\right)$ guarantees that $F^{*}(x) \geq(x-c)+F^{*}\left(x_{0}\right)$ is satisfied on the entire $\mathbb{R}_{+}$. Thus, we find that the proposed value function satisfies the conditions of part (a) of Theorem 2.1 in Øksendal 1999 and, therefore, that $V(x) \leq F^{*}(x)$ for all $x \in \mathbb{R}_{+}$, thus completing the proof.

\section{E Proof of Theorem 3.5}

Proof. Assume that our conditions are satisfied and denote as $X_{t}^{x}$ the (flow of the) solution of the stochastic differential equation

$$
X_{t}^{x}=x+\int_{0}^{t} \mu\left(X_{s}^{x}\right) d s+\int_{0}^{t} \sigma\left(X_{s}^{x}\right) d W_{s}
$$

Given our smoothness-assumptions on the drift $\mu(x)$ and the infinitesimal diffusion coefficient $\sigma(x)$ imply that the process $Y_{t}^{1}=\frac{\partial X_{t}^{x}}{\partial x}$ constitutes the strong solution of the stochastic differential equation (cf. Øksendal, 1998, pp. 66-70)

$$
Y_{t}^{1}=1+\int_{0}^{t} \mu^{\prime}\left(X_{s}^{x}\right) Y_{s}^{1} d s+\int_{0}^{t} \sigma^{\prime}\left(X_{s}^{x}\right) Y_{s}^{1} d W_{s}
$$

and can, therefore, be expressed as

$$
Y_{t}^{1}=\exp \left(\int_{0}^{t} \mu^{\prime}\left(X_{s}^{x}\right) d s\right) M_{t}
$$

where

$$
M_{t}=\exp \left(\int_{0}^{t} \sigma^{\prime}\left(X_{s}^{x}\right) d W_{s}-\frac{1}{2} \int_{0}^{t} \sigma^{\prime 2}\left(X_{s}^{x}\right) d s\right)
$$

is a positive martingale. Consequently, the assumed concavity of the drift $\mu(x)$, the positivity of the martingale $M_{t}$, and the monotonicity of the solution $X_{t}^{x}$ as a function of the initial state $x$ then imply that $X_{t}^{x}$ is concave in terms of $x$. Define the convex combination $\hat{x}$ as $\hat{x}=\lambda x+(1-\lambda) y$, where $x, y \in \mathbb{R}_{+}$and $\lambda \in[0,1]$. The concavity of 
$X_{t}^{x}$ as a function of $x$ and the monotonicity and concavity of the mapping $\pi(x)$ imply that

$$
\pi\left(X_{t}^{\hat{x}}\right) \geq \pi\left(\lambda X_{t}^{x}+(1-\lambda) X_{t}^{y}\right) \geq \lambda \pi\left(X_{t}^{x}\right)+(1-\lambda) \pi\left(X_{t}^{y}\right)
$$

which finally proves the alleged concavity of the expected cumulative present value $\left(R_{r} \pi\right)(x)$. The linearity of the payoff $x-c$ implies that $u(t, x)$ is non-decreasing and concave as a function of $x$. The monotonicity and concavity of $v(t, x)$ as a function of the current state $x$ follows then from the analogous properties for $\left(R_{r} \pi\right)(x)$ and $u(t, x)$.

It remains to establish that increased volatility decreases these values. To accomplish this task, denote now the expected cumulative present value of the revenue flow $\pi(x)$ in the presence of the more volatile process as $\left(\tilde{R}_{r} \pi\right)(x)$ and the differential operator associated to the more volatile process, $\tilde{X}_{t}$, as

$$
\tilde{\mathcal{A}}=\frac{1}{2} \tilde{\sigma}^{2}(x) \frac{d^{2}}{d x^{2}}+\mu(x) \frac{d}{d x} .
$$

Since $\left(R_{r} \pi\right)(x)$ satisfies the ordinary second order differential equation

$$
\frac{1}{2} \sigma^{2}(x)\left(R_{r} \pi\right)^{\prime \prime}(x)+\mu(x)\left(R_{r} \pi\right)^{\prime}(x)-r\left(R_{r} \pi\right)(x)+\pi(x)=0,
$$

we find by the concavity of $\left(R_{r} \pi\right)(x)$ that

$$
\left(\tilde{\mathcal{A}}\left(R_{r} \pi\right)\right)(x)-r\left(R_{r} \pi\right)(x)+\pi(x)=\frac{1}{2}\left(\tilde{\sigma}^{2}(x)-\sigma^{2}(x)\right)\left(R_{r} \pi\right)^{\prime \prime}(x) \leq 0 .
$$

Consequently, we have

$$
\begin{aligned}
0 \leq \mathbf{E}_{x}\left[e^{-r T_{n}}\left(R_{r} \pi\right)\left(\tilde{X}_{T_{n}}\right)\right] & =\left(R_{r} \pi\right)(x)+\mathbf{E}_{x} \int_{0}^{T_{n}} e^{-r s}\left[\left(\tilde{\mathcal{A}}\left(R_{r} \pi\right)\right)\left(\tilde{X}_{s}\right)-r\left(R_{r} \pi\right)\left(\tilde{X}_{s}\right)\right] d s \\
& \leq\left(R_{r} \pi\right)(x)-\mathbf{E}_{x} \int_{0}^{T_{n}} e^{-r s} \pi\left(\tilde{X}_{s}\right) d s,
\end{aligned}
$$

where $T_{n}=n \wedge \inf \left\{t \geq 0: \tilde{X}_{t} \notin\left(n^{-1}, n\right)\right\}, n \in \mathbb{N}$, is an almost surely finite stopping time. Letting $n \rightarrow \infty$ and invoking monotone convergence then implies that $\left(R_{r} \pi\right)(x) \geq$ $\left(\tilde{R}_{r} \pi\right)(x)$, so that increased volatility decreases the expected cumulative present value accrued from amenity services. To establish that increased volatility decreases $u(t, x)$ we first denote as $\tilde{u}(t, x)$ the value in the presence of the more volatile process $\tilde{X}_{t}$. It is now a direct consequence of the Feynman-Kač-theorem that $u(t, x)$ is the solution of the boundary value problem (cf. Øksendal 1998, p. 135)

$$
\begin{aligned}
(\mathcal{A} u)(t, x)-r u(t, x) & =\frac{\partial u}{\partial t}(t, x), \quad(t, x) \in \mathbb{R}_{+}^{2}, \\
u(0, x) & =x-c, \quad x \in \mathbb{R}_{+} .
\end{aligned}
$$

The concavity of $u(t, x)$ now implies that

$$
(\mathcal{A} u)(t, x)-r u(t, x)-u_{t}(t, x)=\frac{1}{2}\left(\tilde{\sigma}^{2}(x)-\sigma^{2}(x)\right) u_{x x}(t, x) \leq 0 .
$$


Applying Itô's theorem on the functional $e^{-r s} u\left(t-s, \tilde{X}_{s}\right)$ and invoking the boundary condition $u(0, x)=x-c$ then yields

$$
\begin{aligned}
\mathbf{E}\left[e^{-r t}\left(\tilde{X}_{t}-c\right)\right] & =u(t, x)+\mathbf{E} \int_{0}^{t} e^{-r s}\left((\tilde{\mathcal{A}} u)\left(t-s, \tilde{X}_{s}\right)-r u\left(t-s, \tilde{X}_{s}\right)-u_{s}\left(t-s, \tilde{X}_{s}\right)\right) d s \\
& \leq u(t, x)=\mathbf{E}\left[e^{-r t}\left(X_{t}-c\right)\right]
\end{aligned}
$$

proving the alleged negativity of the sign of the relationship between volatility and $u(t, x)$. Proving that increased volatility decreases $v(t, x)$ is analogous.

\section{F $\quad$ Proof of Theorem 3.6}

Proof. Under the assumptions of our theorem the stochastic differential equation describing the dynamics of the value of a forest stand read as

$$
d X_{t}^{x}=\mu\left(X_{t}^{x}\right) d t+\sigma X_{t}^{x} d W_{t}, \quad X_{0}^{x}=x
$$

Multiplying this equation with the (integrating) factor $Y_{t}=e^{\frac{1}{2} \sigma^{2} t-\sigma W_{t}}$ implies that (F.1) can be re-expressed as

$$
Y_{t} X_{t}^{x}=x+\int_{0}^{t} Y_{s} \mu\left(X_{s}^{x}\right) d s, \quad X_{0}=x .
$$

Standard differentiation then yields that

$$
\frac{\partial X_{t}^{x}}{\partial x}=e^{\int_{0}^{t} \mu^{\prime}\left(X_{s}^{x}\right) d s} M_{t},
$$

where $M_{t}=Y_{t}^{-1}=e^{-\frac{1}{2} \sigma^{2} t+\sigma W_{t}}$ is a positive exponential martingale. Combining this result with the concavity of the drift implies that $X_{t}^{x}$ is increasing and concave as a mapping of its initial state $x$. Hence, the assumed monotonicity and convexity properties of the revenue flow $\pi(x)$ imply that $\pi\left(X_{t}^{x}\right)$ is decreasing and convex as a function of the initial state $x$ and that $\left(R_{r} \pi\right)(x)$ is decreasing and convex as a function of the initial state $x$ as well. The positivity of the sign of the relationship between increased volatility and the expected cumulative present value, accrued from amenity services, can now be established by relying on analogous arguments with the ones presented in the proof of Theorem 3.5.

Consider now the marginal expected cumulative revenues accrued from amenity services. Standard differentiation now yields

$$
\left(R_{r} \pi\right)^{\prime}(x)=E \int_{0}^{\infty} e^{-\int_{0}^{s}\left(r-\mu^{\prime}\left(X_{t}^{x}\right)\right) d t} \pi^{\prime}\left(X_{s}^{x}\right) M_{s} d s
$$

Defining the equivalent measure $\mathbb{Q}$ with the likelihood ratio $d \mathbb{Q} / d \mathbb{P}=M_{t}$ then implies that the marginal expected cumulative revenues accrued from amenity services can be re-expressed as

$$
\left(R_{r} \pi\right)^{\prime}(x)=E \int_{0}^{\infty} e^{-\int_{0}^{s}\left(r-\mu^{\prime}\left(\bar{X}_{t}^{x}\right)\right) d t} \pi^{\prime}\left(\bar{X}_{s}^{x}\right) d s,
$$


where $\bar{X}_{t}^{x}$ evolves under $\mathbb{P}$ (by the strong uniqueness of solutions) according to the dynamics described by the stochastic differential equation

$$
d \bar{X}_{t}^{x}=\left(\mu\left(\bar{X}_{t}^{x}\right)+\sigma^{2} \bar{X}_{t}^{x}\right) d t+\sigma \bar{X}_{t}^{x} d W_{t}, \quad \bar{X}_{0}^{x}=x .
$$

It is now a straightforward consequence of the analysis above that the assumed concavity of the drift $\mu(x)$ implies that $\mu(x)+\sigma^{2} x$ is concave as well and, therefore, that $\bar{X}_{t}^{x}$ is increasing and concave as a mapping of its initial state $x$. This finding together with the assumed monotonicity and convexity of the factor $\mu^{\prime}(x)$ now implies that $e^{\int_{0}^{t} \mu^{\prime}\left(\bar{X}_{s}\right) d s}$ is decreasing and convex as a function of the initial state $x$. Similarly, the assumed monotonicity and concavity of $\pi^{\prime}(x)$ implies that the factor $\pi^{\prime}\left(\bar{X}_{t}\right)$ is increasing and concave in $x$. Combining these two observations then finally imply that the mapping $\left(R_{r} \pi\right)^{\prime}(x)$ is non-decreasing and concave in $x$. The negativity of the sign of the relationship between increased volatility and the marginal value $\left(R_{r} \pi\right)^{\prime}(x)$ follows from the proof of Theorem 3.5. It remains to establish that increased volatility decreases the difference $\left(R_{r} \pi\right)(x)-\left(R_{r} \pi\right)\left(x_{0}\right)$. The fundamental theorem of integral calculus implies that

$$
\left(R_{r} \pi\right)(x)-\left(R_{r} \pi\right)\left(x_{0}\right)=\int_{x_{0}}^{x}\left(R_{r} \pi\right)^{\prime}(y) d y
$$

from which the result follows by the negativity of the sign of the relationship between increased volatility and the marginal value $\left(R_{r} \pi\right)^{\prime}(x)$.

\section{G Proof of Theorem 3.8}

Proof. Denote as $\tilde{F}(x)$ the value of the optimal rotation policy in the presence of greater volatility $\tilde{\sigma}(x)$. If $F(x)$ is concave, then

$$
(\tilde{\mathcal{A}} F)(x)-r F(x)+\pi(x) \leq \frac{1}{2}\left[\tilde{\sigma}^{2}(x)-\sigma^{2}(x)\right] F^{\prime \prime}(x) \leq 0
$$

for all $x \in \mathbb{R}_{+}$. Moreover, $F(x)$ satisfies the inequality $F(x) \geq F\left(x_{0}\right)+(x-c)$ for all $x \in \mathbb{R}_{+}$as well and, consequently, satisfies the sufficient variational inequalities guaranteeing that $F(x) \geq \tilde{F}(x)$ (cf. Øksendal, 1999).

\section{H Proof of Corollary 4.2}

Proof. As was established in Theorem 3.4, the value $V(x)$ satisfies the inequalities $((\mathcal{A}-r) V)(x)+\pi(x) \leq 0$ and $V(x) \geq(x-c)+V\left(x_{0}\right) \geq(x-c)$ for all $x \in \mathbb{R}_{+}$. Consequently, we find that for any $x \in \mathbb{R}_{+}$we have

$$
\begin{aligned}
\mathbf{E}_{x}\left[e^{-r \tau_{n}}\left(X_{\tau_{n}}-c\right)\right] & \leq \mathbf{E}_{x}\left[e^{-r \tau_{n}} V\left(X_{\tau_{n}}\right)\right]=V(x)+\mathbf{E}_{x} \int_{0}^{\tau_{n}} e^{-r s}((\mathcal{A}-r) V)\left(X_{s}\right) d s \\
& \leq V(x)-\mathbf{E}_{x} \int_{0}^{\tau_{n}} e^{-r s} \pi\left(X_{s}\right) d s,
\end{aligned}
$$

where $\tau_{n}=n \wedge \inf \left\{t \geq 0: X_{t} \geq n\right\} \wedge \tau, n \in \mathbb{N}$, is an almost surely finite stopping time. Letting $n \rightarrow \infty$ and invoking Fatou's theorem and monotone convergence then yields

$$
V(x) \geq \mathbf{E}_{x}\left[e^{-r \tau}\left(X_{\tau}-c\right)+\mathbf{E}_{x} \int_{0}^{\tau} e^{-r s} \pi\left(X_{s}\right) d s\right]
$$


completing the proof. 


\section{CESifo Working Paper Series}

(for full list see www.cesifo.de)

792 Paul De Grauwe and Marianna Grimaldi, The Exchange Rate in a Model with Heterogeneous Agents and Transactions Costs, October 2002

793 Guido Friebel and Mariassunta Giannetti, Fighting for Talent: Risk-shifting, Corporate Volatility, and Organizational Change, October 2002

794 Jan Erik Askildsen, Badi H. Baltagi, and Tor Helge Holmås, Will Increased Wages Reduce Shortage of Nurses? A Panel Data Analysis of Nurses' Labour Supply, October 2002

795 Marko Köthenbürger and Panu Poutvaara, Social Security Reform and Intergenerational Trade: Is there Scope for a Pareto-Improvement?, October 2002

796 Paul De Grauwe and Laura Rinaldi, A Model of the Card Payment System and the Interchange Fee, October 2002

797 Volker Böhm and Tomoo Kikuchi, Dynamics of Endogenous Business Cycles and Exchange Rate Volatility, October 2002

798 Mariam Camarero, Javier Ordóñez, and Cecilio Tamarit, The Euro-Dollar Exchange Rate: Is it Fundamental?, October 2002

799 Misa Tanaka, How Do Bank Capital and Capital Adequacy Regulation Affect the Monetary Transmission Mechanism?, October 2002

800 Jörg Baten and Andrea Wagner, Autarchy, Market Disintegration, and Health: The Mortality and Nutritional Crisis in Nazi Germany, 1933-1937, October 2002

801 Saku Aura, Uncommitted Couples: Some Efficiency and Policy Implications of Marital Bargaining, October 2002

802 Wolfram F. Richter, Delaying Integration of Immigrant Labor for the Purpose of Taxation, October 2002

803 Gil S. Epstein and Shmuel Nitzan, The Politics of Randomness, October 2002

804 John Hassler and José V. Rodriguez Mora, Should UI Benefits Really Fall over Time?, October 2002

805 Friedrich Breyer and Stefan Felder, The Dead-anyway Effect Revis(it)ed, October 2002

806 Assar Lindbeck and Solveig Wikström, E-exchange and the Boundary between Households and Organizations, November 2002

807 Dieter Bös, Contests Among Bureaucrats, November 2002 
808 Steven Brakman, Harry Garretsen, and Marc Schramm, The Strategic Bombing of German Cities during World War II and its Impact on City Growth, November 2002

809 Florian Englmaier and Achim Wambach, Contracts and Inequity Aversion, November 2002

810 Sarbajit Sengupta, Delegating Recruitment under Asymmetric Information, December 2002

811 Rajshri Jayaraman, On the Partial Public Provision of a Private Good, December 2002

812 Stéphanie Stolz, Banking Supervision in Integrated Financial Markets: Implications for the EU, December 2002

813 Christian Keuschnigg, Taxation of a Venture Capitalist with a Portfolio of Firms, December 2002

814 Inés Macho-Stadler and David Pérez-Castrillo, Settlement in Tax Evasion Prosecution, December 2002

815 Rainer Niemann and Dirk Simons, Costs, Benefits, and Tax-induced Distortions of Stock Option Plans, December 2002

816 Jan-Egbert Sturm and Barry Williams, Deregulation, Entry of Foreign Banks and Bank Efficiency in Australia, December 2002

817 V. Anton Muscatelli, Patrizio Tirelli, and Carmine Trecroci, Monetary and Fiscal Policy Interactions over the Cycle: Some Empirical Evidence, December 2002

818 Claude Hillinger, A General Theory of Price and Quantity Aggregation and Welfare Measurement, December 2002

819 Erkki Koskela and Ronnie Schöb, Optimal Capital Taxation in Economies with Unionised and Competitive Labour Markets, December 2002

820 Sheilagh Ogilvie, Guilds, Efficiency, and Social Capital: Evidence from German ProtoIndustry, December 2002

821 Hans Gersbach and Verena Liessem, Financing Democracy, December 2002

822 Costas Hadjiyiannis, Panos Hatzipanayotou, and Michael S. Michael, Optimal Tax Policies with Private-Public Clean-Up, Cross-Border Pollution and Capital Mobility, December 2002

823 François Ortalo-Magné and Sven Rady, Homeownership: Low Household Mobility, Volatile Housing Prices, High Income Dispersion, December 2002

824 Syed M. Ahsan and Panagiotis Tsigaris, Measuring the Social Discount Rate under Uncertainty: A Methodology and Application, December 2002 
825 Kai A. Konrad, Altruism and Envy in Contests: An Evolutionarily Stable Symbiosis, December 2002

826 Robert S. Chirinko and Huntley Schaller, A Revealed Preference Approach to Understanding Corporate Governance Problems: Evidence from Canada, December 2002

827 Geir B. Asheim, Green National Accounting for Welfare and Sustainability: A Taxonomy of Assumptions and Results, December 2002

828 Andrea Gebauer, Chang Woon Nam, and Rüdiger Parsche, Lessons of the 1999 Abolition of Intra-EU Duty Free Sales for Eastern European EU Candidates, December 2002

829 Giacomo Corneo, Work and Television, December 2002

830 Vivek H. Dehejia and Yiagadeesen Samy, Trade and Labour Standards - Theory, New Empirical Evidence, and Policy Implications, December 2002

831 Geir B. Asheim and Wolfgang Buchholz, A General Approach to Welfare Measurement through National Income Accounting, December 2002

832 Aaron Tornell and Frank Westermann, The Credit Channel in Middle Income Countries, January 2003

833 Gebhard Flaig, Time Series Properties of the German Monthly Production Index, January 2003

834 Campbell Leith and Jim Malley, Estimated Open Economy New Keynesian Phillips Curves for the G7, January 2003

835 Burkhard Heer and Bernd Süssmuth, Inflation and Wealth Distribution, January 2003

836 Erkki Koskela and Leopold von Thadden, Optimal Factor Taxation under Wage Bargaining - A Dynamic Perspective, January 2003

837 Carola Grün and Stephan Klasen, Growth, Income Distribution, and Well-Being: Comparisons across Space and Time, January 2003

838 Robert S. Chirinko and Ulf von Kalckreuth, On the German Monetary Transmission Mechanism: Interest Rate and Credit Channels for Investment Spending, January 2003

839 Sascha O. Becker, Andrea Ichino, and Giovanni Peri, How Large is the "Brain Drain" from Italy?", January 2003

840 Albert Berry and John Serieux, All About the Giants: Probing the Influences on Growth and Income Inequality at the End of the $20^{\text {th }}$ Century, January 2003

841 Robert Fenge and Martin Werding, Ageing and the Tax Implied in Public Pension Schemes: Simulations for Selected OECD Countries, January 2003 
842 Robert Fenge and Martin Werding, Ageing and Fiscal Imbalances Across Generations: Concepts of Measurement, January 2003

843 Giovanni Andrea Cornia, The Impact of Liberalisation and Globalisation on Income Inequality in Developing and Transitional Economies, January 2003

844 Peter Fredriksson and Per Johansson, Program Evaluation and Random Program Starts, January 2003

845 Bernd Hayo and Matthias Wrede, Fiscal Equalisation: Principles and an Application to the European Union, January 2003

846 Syed M. Ahsan and Jaideep Oberoi, Inequality, Well-being and Institutions in Latin America and the Caribbean, January 2003

847 Chang Woon Nam and Doina Maria Radulescu, The Role of Tax Depreciation for Investment Decisions: A Comparison of European Transition Countries, January 2003

848 V. Bhaskar and Steinar Holden, Wage Differentiation via Subsidised General Training, January 2003

849 Paloma Lopez-Garcia, Labour Market Performance and Start-up Costs: OECD Evidence, January 2003

850 Christian Keuschnigg and Soren Bo Nielsen, Public Policy for Start-up Entrepreneurship with Venture Capital and Bank Finance, January 2003

851 Yin-Wong Cheung, Menzie D. Chinn, and Eiji Fujii, China, Hong Kong, and Taiwan: A Quantitative Assessment of Real and Financial Integration, January 2003

852 Gregory D. Hess, The Economic Welfare Cost of Conflict: An Empirical Assessment, February 2003

853 Douglas J. Cumming and Jeffrey G. MacIntosh, Comparative Venture Capital Governance. Private versus Labour Sponsored Venture Capital Funds, February 2003

854 Eckhard Janeba and John Douglas Wilson, Decentralization and International Tax Competition, February 2003

855 Tapio Palokangas, Capital Accumulation and Employment Cycles in a Model of Creative Destruction, February 2003

856 Brendan Walsh, When Unemployment Disappears: Ireland in the 1990s, February 2003

857 Luis H. R. Alvarez and Erkki Koskela, A General Approach to the Stochastic Rotation Problem with Amenity Valuation, February 2003 